being a British subject and under thirty years of age at December 31 in that year, shows the most promise as indicated by his or her published work.

The Permanent Exhibition of Modern Science, Pretoria

Mr. Murray Schoonraad has been appointed superintendent of the Permanent Exhibition of Modern Science, Pretoria. Mr. Schoonraad, an official of the Atomic Energy Board, has been organizer of the Exhibition in his private capacity since its inception in August 1960. He was educated at the Pretoria Boys High School and later studied at the University of South Africa. For a number of years Mr. Schoonraad was employed by the Council of Scientific and Industrial Research. The Permanent Exhibition of Modern Science in Pretoria is the first and only science museum on the whole continent of Africa and has encouraged many South African children to take up science as a career. The museum is the contribution of the South African Association for the Advancement of Science to South Africa's fiftieth anniversary. The hall in which the exhibits are housed has been provided by the Pretoria City Council and covers an area of 30,000 sq. ft. at the Pretoria Showgrounds. Exhibits have been erected by scientific bodies, most of them working in and around Pretoria.

\section{The Wellcome Trust : Grants for Medical Research}

Ir has been announced by the Wellcome Trustees that grants were made to assist research on human and animal medicine during the half-year ended on March 31 to the following:

United Kingdom: University of Glasgow (Profs. C. M. Yonge and W. I. M. McIntyre), $£ 45,240$ to build a unit for experimental parasitology; University of Oxford (Prof. Geoffrey W. Harris), $£ 35,000$ to adapt the Department of Human Anatomy for his research needs; University of Birmingham (Prof. J. R. Squire), $£ 31,000$ to establish a unit for the investigation of whole-body radiation; The London Hospital (Mr. H. D. Ritchie), $£ 25,000$ to build a high-pressure chamber for surgical research; University of Leeds (Prof. J. V. Dodd), $£ 20,000$ to enlarge the Marine Research Laboratory at Robin Hood's Bay; Royal College of Veterinary Surgeons, London, $£ 17,500$ to build and equip libraries for research in veterinary medicine and its history; University of Birmingham (Profs. F. A. R. Stammers and A. L. d'Abreu), $£ 14,000$ to build animal accommodation in the new Clinical Research Block at the Queen Elizabeth Hospital; St. Mary's Hospital Medical School, London (Dr. V. H. T. James), $£ 6,000$ to purchase a liquid scintillation spectrometer and ancillaries; The Royal Free Hospital, London (Prof. S. Sherlock), £5,750 to purchase a scintillation spectrometer and ancillaries; School of Pharmacy, London (Dr. G. B. West), $£ 5,560$ to purchase a scintillation spectrometer and ancillaries; University of East Anglia (Dr. A. R. Katritzky), $£ 4,500$ towards the purchase of a nuclear magnetic resonance spectrometer; University of Cambridge (Prof. J. S. Mitchell), $£ 3,500$ to purchase an integrating microdensitometer; University of Liverpool (Prof. C. Gray), $£ 3,500$ to purchase a four-chaninel recorder.

Overseas : University of Melbourne (Prof. M. Ewing), $£ 14,000$ to construct an operating theatre at the Royal Melbourne Hospital; Johns Hopkins University, Baltimore (Prof. E. Bueding), $£ 20,000$ towards the cost of new laboratories for research in schistosomiasis; University of Auckland (Prof. R. E. F. Matthews), $£ 11,000$ to provide an electron microscope for research in microbiology; University of Melbourne (Dr. G. Burnstock), $£ 9,600$ to purchase equipment for neurophysiological research; University of Lucknow (Prof. S. S. Misra), $£ 4,000$ to equip a metabolic research unit.

Together with grants of smaller size and Welleome Research Travel Grants, the total sum allocated by the Trustees in that period amounted to approximately $£ 500,000$.
The Pergamon Scholarship for Graduate Scientists to read Arts Subjects

WITH the view of establishing a bridge between the arts and the sciences, Pergamon Press, Oxford, has established a postgraduate scholarship. The new scholarship, to be known as the Pergamon Postgraduate Scholarship, is open to male scientists who have obtained a first or good second class in final honours examinations at any university in the United Kingdom during 1963. It is tenable at Keble College, Oxford, for the study of an arts subject. The subject should lie in the field of human studies such as history, philosophy, economics, modern languages and literature, anthropology, archæology, singly or in any combination approved by the College, according to the choice and ability of the scholar. The purpose of the award is therefore to equip a fully qualified scientist with the elements of an arts subject. This should enable him later to communicate more effectively with persons of non-scientific training who commonly find their vocation as Civil Servants, industrialists, business men, administrators, accountants, lawyers, teachers, writers and politicians. His course of study should give him some insight into such men's way of thinking and reasoning, their reactions and their approaches to the solving of problems. In particular, he should learn to appreciate the importance of the human factor in making decisions. The period of study will be four terms, but will include work during the long vacations. The emoluments for the whole period will be approximately $£ 900$. At the end of this period the scholar will take a College examination. A certificate in the form of a final report will be issued. At the present stage it is not intended that he should take a university degree or diploma. Further information can be obtained from the Warden, the Rev. A. M. Farrer, Keble College, Oxford.

\section{University and Technical College Expansion in Britain}

IN speaking on April 9 in the debate in the House of Commons on the Budget resolutions and the economic situation, the Chief Secretary to the Treasury, Mr. J. Boyd-Carpenter, pointed out that expenditure on the universities had risen from $£ 36$ million in 1951-52 to more than $\$ 140$ million in the current year. During the same period, the number of students had risen from 83,500 to 116,000. He emphasized that the Government was anxious that financial limitations should not restrict university expansion. The vote for 1963-64 provided for capital expenditure for building $£ 38$ million, as against the original estimate for $1962-63$ of $£ 26.4$ million. In addition to the revision of the building programme-with increases for starts in 1964 and 1965 announced on March 19, Mr. Boyd-Carpenter said that the vote for 1963-64 provided $£ 66.4$ million for recurrent expenditure, compared with £51.5 million for 1962-63, and that the Government had now decided to advance the promised review of the university situation so that any additions to grants could take effect for the university financial year beginning on August 1, 1963: He had already asked the University Grants Committee for advice and hoped to be able to make a statement very soon. There were also 10,000 students in the colleges of advanced technology, compared with none eleven years ago, and it was hoped there would be about 15,000 in five years' time. In the universities, colleges of advanced technology and teacher training colleges there were now 212,000 places, compared with 120,000 in 1951-52, and on present plans there would be 288,000 in $1966-67$.

\section{Oceanography in Germany}

THE new research vessel of the German Forschungsgemeinschaft and German Hydrographic Institute is to be christened Meteor II and will so preserve a name having an honoured and intimate connexion with the sea. From the earlier research vessel of the name, the 